\title{
Gamma-aminobutyric acid ameliorates gamma rays-induced oxidative stress in the small intestine of rats
}

\author{
Amr M. Abd El-Hady ${ }^{1 *}$, Hanan S. Gewefel ${ }^{1}$, Manal A. Badawi ${ }^{2}$ and Noaman A. Eltahawy ${ }^{3}$
}

\begin{abstract}
Background: The current study aimed to evaluate the role of gamma-amino butyric acid (GABA) in modulating histopathological and biochemical disturbances in the rat's small intestine following gamma radiation exposure.

Results: The results showed that whole body gamma irradiation (6 Gy) of rats induced mucosal damage, hemorrhage, increased cellularity of the lamina propria layer with areas of complete ulcerations. Histopathological changes were associated with a significant increase in malondialdehyde (MDA) and advanced oxidation protein products (AOPPs). In parallel, a significant decrease in catalase (CAT) and glutathione peroxidase (GSH-Px) activities was demonstrated. Administration of GABA ( $200 \mathrm{mg} / \mathrm{kg}$ body weight GABA daily via gastric gavage for three consecutive weeks) after irradiation of rats has significantly improved the oxidant/antioxidant status which was associated with regeneration of the small intestinal cell structure.

Conclusion: Gastric administration of GABA was found to offer an advantageous treatment against gamma irradiation-induced small intestine oxidative stress in rats, probably by utilizing ameliorative effects via its antioxidant and free radical-scavenging activities. Its mechanisms need to be further investigated.
\end{abstract}

Keywords: Gamma radiation, Small intestine, GABA, Paneth cells, Oxidative stress

\section{Background}

Radiation is a therapeutic method for the treatment of the variety of tumors, but its side effects on the normal tissues limit its effectiveness (Grdina, Murley, \& Kataoka, 2002). The gastrointestinal (GI) tract is one of the most radiosensitive organs in the body. Radiation exposure damages the intestinal crypts and endocrine glands of the GI tract (Hauer-Jensen, Wang, Boerma, Fu, \& Denham, 2007). Early radiation enteropathy occurs during radiotherapy as a result of intestinal crypts cell death, lacking the villus epithelium replacement and mucosal inflammation processes (Hauer-Jensen, Denham, \& Andreyev, 2014).

Damage of intestinal villi could be one of the major problems following radiotherapy process which in turn leads to reduction or loss of the digestive enzymes

\footnotetext{
* Correspondence: amreem2005@yahoo.com

${ }^{1}$ Radiological Imaging Technology Department, Faculty of Applied Medical Sciences, Misr University for Science and Technology (MUST), 6th of October, Giza, Egypt

Full list of author information is available at the end of the article
}

resulting in nutrient malabsorption (Czito \& Willett, 2010). Cellular radiation damage develops due to the direct or indirect action of radiation on the DNA molecules (Desouky, Ding, \& Zhou, 2015; Jagetia \& Reddy, 2005).

Besides the digestion and absorption of nutrients, the small intestinal epithelium also contributes in host defense processes and in the elimination of pathogens (Müller, Autenrieth, \& Peschel, 2005). Paneth cell function was a puzzle, but they are now very important in innate intestinal defense as regulators of microbial concentration in the small intestine and play a role in the protection of adjacent intestinal stem cells (Elphick \& Mahida, 2005). Paneth cells have several apical cytoplasmic granules which, on cell stimulation, can be discharged into the crypt lumen (Ouellette, Satchell, Hsieh, Hagen, \& Selsted, 2000).

The present study explores the potent of gammaaminobutyric acid (GABA) treatment for the deleterious effects of radiation where GABA is considered to be the major inhibitory neurotransmitter in the central nervous system (Hori et al., 2013). GABA results from glutamate 
by decarboxylation process through glutamic acid decarboxylase activity, and it produces biological effects through stimulation of $\mathrm{A}$ and $\mathrm{B}$ receptors of GABA (Watanabe, Maemura, Kanbara, Tamayama, \& Hayasaki, 2002). Both A and B receptors are found in nonneuronal cells of gut organs (Dong et al., 2006). GABA is found in the rat jejunum epithelial cells (Wang, Watanabe, Zhu, \& Maemura, 2004). It has paracrine and autocrine properties in various peripheral tissues (Watanabe et al., 2002). It has a role in the inhibition of many inflammatory cellular reactions (Tian et al., 2011) and has antidiabetic (Soltani et al., 2011), antioxidant, and free radical-scavenging properties (Deng et al., 2013). GABA is found all over the GI tract, in endocrine-like cells, and in enteric nerves, and it is considered as a neurotransmitter with an endocrine GI tract function (Hyland \& Cryan, 2010).

In view of these considerations, the aim of the current study was to evaluate the role of GABA in ameliorating the small intestine architecture resulting from radiationinduced damage. In parallel, the efficacy of GABA on radiation-induced oxidative stress has been evaluated.

\section{Methods}

\section{Animals}

A total of 40 adult male Swiss albino rats (Sprague dawley strain) $(10 \pm 2$ weeks old: weighting $120 \pm 10 \mathrm{~g})$ purchased from the Egyptian Holding Company for Biological Products and Vaccines (Helwan, Cairo, Egypt) were used in the current study. Animals were housed collectively in plastic cages, maintained under standard conditions of light, ventilation, temperature, and humidity, and allowed free access to the standard pellet diet and tap water. For biochemical analysis, animals were sacrificed at 11:00 am $\pm 1 \mathrm{~h}$. All animal procedures were carried out in accordance with the Ethics Committee of the National Research Centre conformed to the "Guide for the Care and Use of Laboratory Animals" published by the US National Institutes of Health.

\section{Irradiation process}

Gamma irradiation of rats was carried out at the National Center for Radiation Research and Technology (NCRRT), Egyptian Atomic Energy Authority (EAEA), Nasr city, Cairo, Egypt, using a Gamma Cell-40 (Cs137), which ensured a homogeneous dose distribution all over the irradiation tray. The dose rate was 0.54 Gy/ min at the time of the experiment. The radiation dose level was 6 Gy single dose (acute dose).

\section{Chemicals}

Gamma-aminobutyric acid (GABA) purchased from Sigma-Aldrich, St Louis, Missouri, USA, in the form of 25-g phials was dissolved in distilled water and given to rats daily by gastric gavages at a dose of $200 \mathrm{mg} / \mathrm{Kg}$ body weight/day (Nakagawa, Yokozawa, Kim, \& Shibahara, 2005) for three successive weeks.

\section{Experimental design}

Experimental animals were randomly divided into four groups $(n=10)$ treated in parallel and classified as following: group I (control group), normal healthy rats administered $1 \mathrm{ml}$ distilled water daily during 3 weeks via gastric gavages; group II (GABA group), normal healthy rats administered GABA (200 mg/Kg body weight/day) daily during 3 weeks via gastric gavages; group III (Irradiated group), whole body gamma-irradiated rats with a single dose (6 Gy) administered $1 \mathrm{ml}$ distilled water daily during 3 weeks via gastric gavages; and group IV (irradiated GABA-treated group), whole body gamma-irradiated rats with a single dose (6 Gy) administered GABA $(200 \mathrm{mg} / \mathrm{Kg}$ body weight/day) daily during 3 weeks via gastric gavages $1 \mathrm{~h}$ post the radiation dose (Figs. 1 and 2).

\section{Sample collection}

By the end of the third week, rats were sacrificed after a fasting period of $12 \mathrm{~h}$ next day to the last dose of administered GABA. Rats were anesthetized with light ether; sacrificed and small segments of jejunum were resected and washed with saline solution for histopathological examinations. Other small segments of the jejunum (10\% $w / v)$ were rapidly excised, homogenized in physiological saline using Teflon homogenizer (Glass-Col, Terre Haute, Ind., USA), and after centrifugation, the supernatant was used for the assessment of oxidative stress. Chemicals and reagents were purchased from Sigma-Aldrich, St Louis, MO, USA. Measurement of absorbance was performed using a T60 UV/VIS spectrophotometer, PG instruments, London, UK.

Tissue samples were fixed in 10\% neutral buffered formalin and Carnoy's fixative and embedded in paraffin. The sections were cut at $5 \mu \mathrm{m}$ and stained with hematoxylin and eosin, Masson's trichrome stain (Bancroft \& Gamble, 2008), periodic acid Schiff's (PAS) method (Drury \& Wallington, 1980), and Feulgen's reaction (Kiernan, 1981). Sections were examined for mucosal injury, inflammation, and congestion and graded in a blinded manner by a pathologist. Sections stained with PAS were evaluated for goblet cell prevalence, and Masson's trichrome-stained sections were used to detect Paneth cells.

\section{Assessment of oxidative stress}

The extent of lipid peroxidation was assayed as described by Yoshioka, Kawada, Shimada, and Mori (1979), advanced oxidation protein products (AOPPs) were determined according to the method of WitkoSarsat et al. (1996), catalase activity was determined as described by Sinha (1972), and glutathione peroxidase 


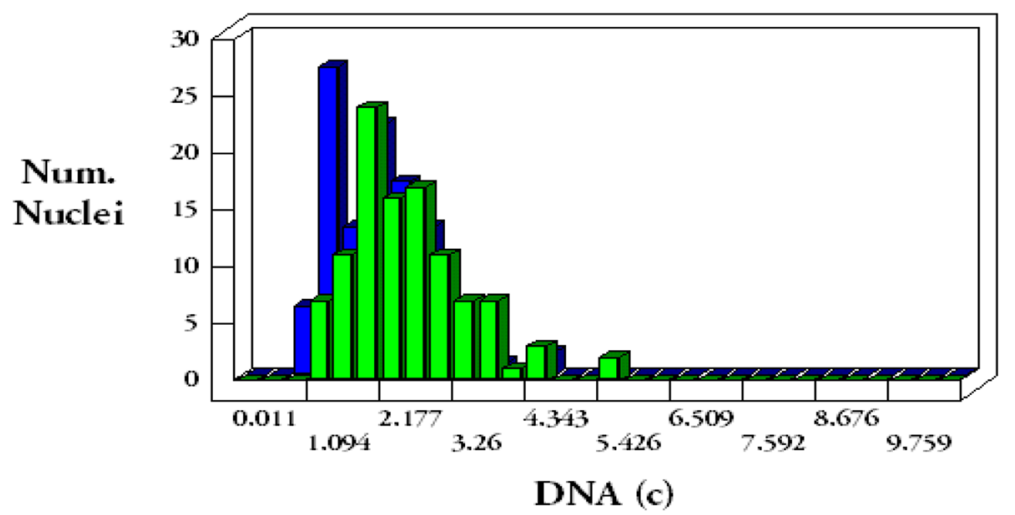

Fig. 1 Combo plot showing a slight shift to the right of irradiated rat DNA histogram (green color) in comparison to control rat histogram (blue color)

(GSH-Px) activity was determined according to the method of Necheles, Boles, and Allen (1968).

\section{Morphometric and cytometric analysis}

For morphometric analysis, four whole circumference $\mathrm{H} \& \mathrm{E}$ sections were examined. The number of villi and crypts per circumference, mucosal thickness, mucosal thickness, and the outer intestinal perimeter were estimated. Ten wellorientated villi per segment were randomly selected and measured for villus height. For the cytometric analysis, nuclear area, proliferation index, and ploidy within random fields were estimated in Feulgen's stained sections. All morphometric and cytometric parameters were done in the pathology department, National Research Centre, Cairo, Egypt, using the Leica Qwin 500 Image Analyzer (LEICA Imaging Systems Ltd., Cambridge, England) which consists of Leica DM-LB microscope with JVC color video camera attached to a computer system Leica Q 500IW. The results were displayed in micrometers and recorded as the mean and standard deviation values.

\section{Statistical analysis}

The SPSS/PC computer program (version 20.0; SPSS Inc., Chicago, IL, USA) was used for statistical analysis of the results. Data were analyzed using one-way analysis of variance (ANOVA) followed by post hoc LSD test. The data were expressed as mean \pm standard deviation (SD). Differences were considered statistically significant at $P<0.05$ (George \& William, 1980).

\section{Results}

\section{Histopathologic observations}

The intestinal specimens obtained from the control and GABA groups were examined showing a normal histological structure of the villi and crypts (Fig. 3a, c) with normal Paneth cells (Figs. 3b, d and 4h, i). The irradiated group showed severe degenerative changes (Figs. 3e, f and $4 \mathrm{j}$ ) where mucosal damage appeared in the form of subepithelial space at the apex of some villi with capillary congestion and hemorrhage; other villi showed massive lifting of the epithelial layer from the lamina propria. Some

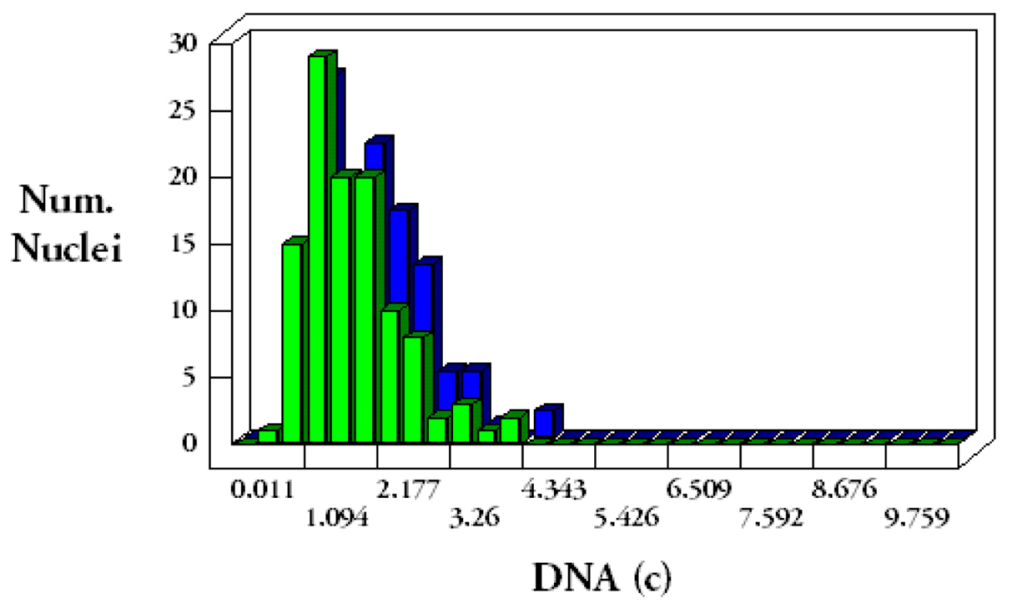

Fig. 2 Combo plot showing an overlap of irradiated and GABA-treated rat DNA histogram (green color) with the control rat histogram (blue color) 


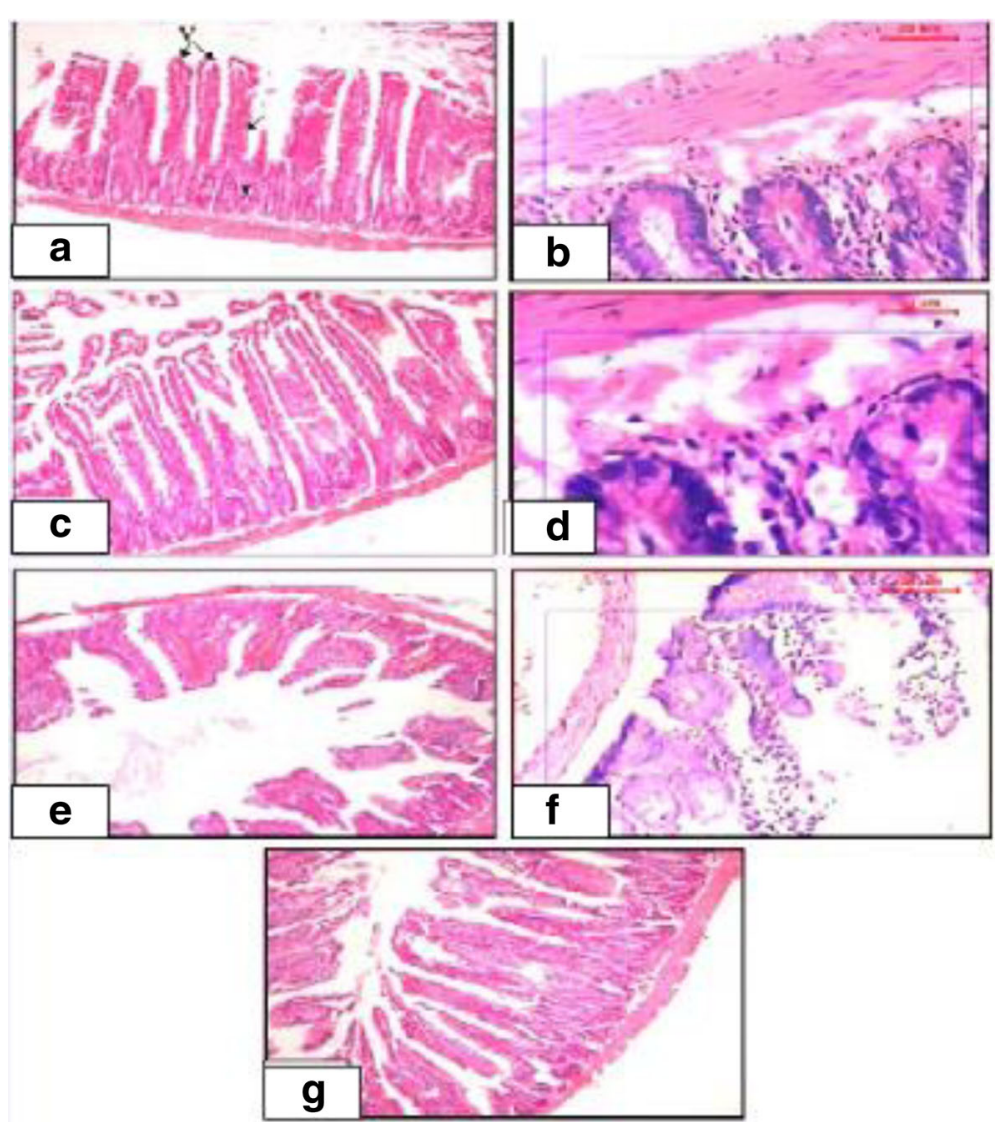

Fig. 3 Photomicrographs of jejunal tissue of the control and treated groups (H\&E). a, c Jejunal tissue of control and GABA-treated rats showing normal appearance of the jejunal mucosa with finger-like projections of the villi $(V)$ and normal crypts of Lieberkühn (arrow head) in between the bases of the villi. Enterocytes appeared with normal tall columnar cells and oval basal nuclei; normal goblet cells (arrow) appeared in between the enterocytes (X 100). b, d Jejunal tissue of control and GABA-treated rats showing normal Paneth cells with their pyramidal shaped and broad base setting on the basement membrane. Paneth cells appeared narrow towards the apical end with their prominent eosinophilic granules at the base of Lieberkühn crypts $(\times 200, \times 400)$. e, $\mathbf{f}$ Jejunal tissues of IR group showing shortened and thickened villi with marked degenerative changes in the epithelial cells. The lamina propria showed congestion, oedema, increased cellularity, and hemorrhage. Few goblet and Paneth cells were seen. Mucosa showed sub-epithelial space at the apex of some villi with capillary congestion; other villi showed massive lifting of the epithelial layer from the lamina propria. Some denuded villi with exposed lamina propria and dilated capillaries were seen $(\times 100, \times 200)$. $\mathbf{g}$ Jejunal tissues of IR + GABA group showing normal villi, but some villi showed apical regions of sub-epithelial lifting with decreased number of goblet cells $(\times 100)$

denuded villi with exposed lamina propria and areas of complete ulceration were seen with increased cellularity of the lamina propria. Radiation-induced atrophy of both crypts and villi with a reduction in the number of both goblet and Paneth cells which appeared degranulated or disappeared totally. These changes were alleviated in irradiated GABA-treated group that showed minimal epithelial cell damage which appeared somewhat similar to that of the control group (Figs. 3g and 4k).

\section{Histochemical observations}

Normal distribution of PAS + ve materials (magenta color) was observed in the jejunal tissue of both the control and GABA-treated rats; this was justified by moderate staining affinity of the PAS +ve materials. Also, increased stainability was noted in goblet cells and their mucin (Fig. 5l, m). Decreased staining affinity of PAS +ve materials was detected in the jejunal tissue of irradiated group except for few numbers of goblet cells with their mucin that showed increased PAS-positive stainability (Fig. 5n). However, a more or less normal PAS + ve material was evident in the jejunal tissue of irradiated GABA-treated group with increased staining affinity of both goblet and Paneth cells (Fig. 5o).

\section{Morphometric and cytometric analysis}

The number of villi and crypts, the thickness of mucosa, musculosa layer, and the outer intestinal circumference decreased significantly after irradiation of rats (irradiated group) compared to those of the control group (Table 1). A high proliferation index, elevated tetraploid value, and increased mean nuclear area were detected in the irradiated 

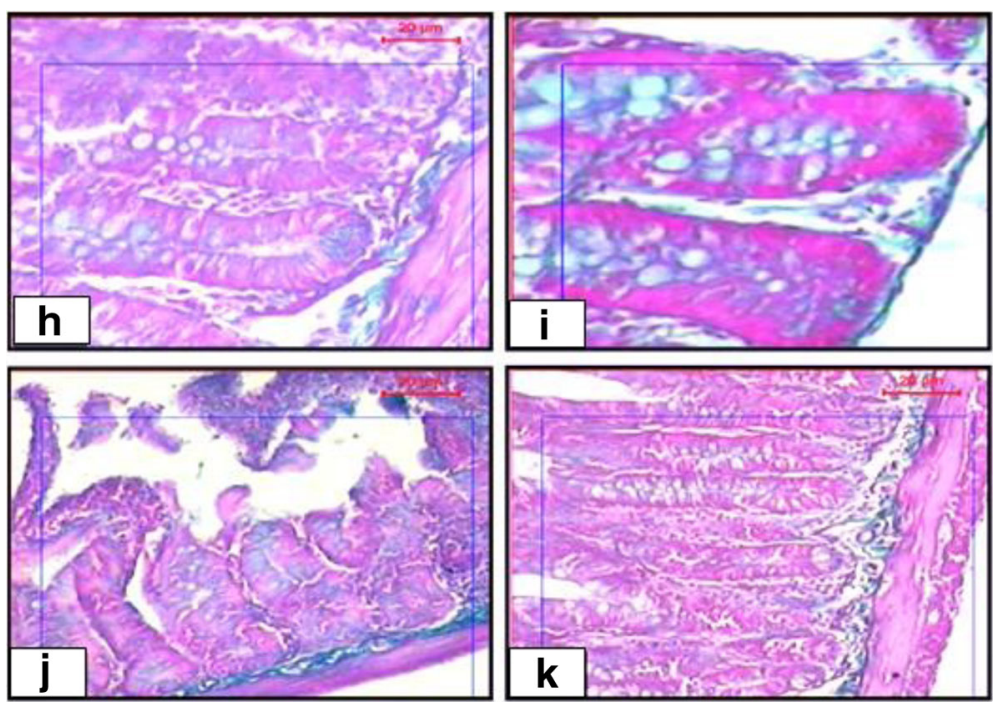

Fig. 4 Photomicrographs of jejunal tissue of the control and treated groups (Masson trichrome). $\mathbf{h}$, $\mathbf{i}$ Jejunal mucosa of a control and GABAtreated rat showing normal Paneth cells with its characteristic granules stained greenish blue $(\times 200, \times 400)$. $\mathbf{j}$ Jejunal mucosa of IR group showing damaged mucosa with complete disappearance of Paneth cells $(\times 200)$. $\mathbf{k}$ Jejunal mucosa of IR + GABA group showing somewhat normal Paneth cells. However, it appears with fewer granules $(\times 100)$

group (Table 2 and Fig. 1). All these parameters were improved in irradiated GABA-treated group (Table 2 and Fig. 2).

\section{Biochemical analysis}

The current results revealed that there was no statistical difference between the control and the GABA groups where CAT, GSH-Px activities, MDA content, and AOPPs levels were within normal range. Whole body gamma irradiation of rats with 6 Gy (irradiated group) induced oxidative stress indicated by a highly significant increase in oxidant biomarkers (AOPPs and MDA) associated with highly significant decrease in the antioxidant (CAT and GSH-Px) values as compared with their respective values of the control group. In irradiated GABA-treated group, there was a highly significant increase in antioxidants activity and highly significant decrease in oxidant biomarkers as
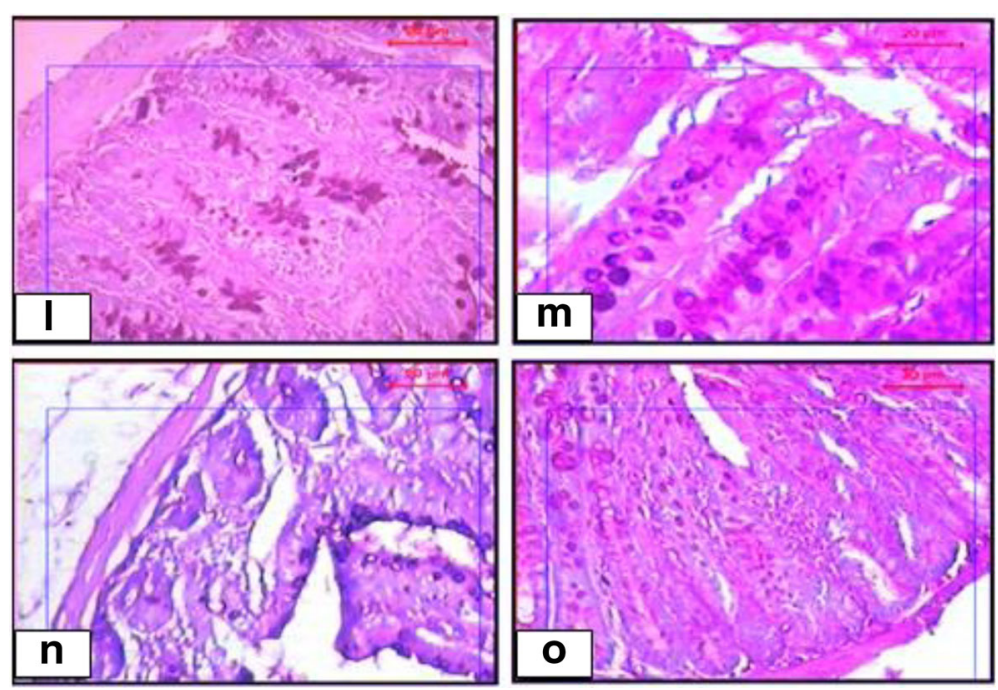

Fig. 5 Photomicrographs of jejunal sections showing distribution of mucopolysaccharides in the jejunal mucosa of the control and treated groups (PAS). I, $\mathbf{m}$ Jejunal section of control and GABA-treated rats showing normal number and distribution of goblet cells with normal mucin content $(\times 100, \times 200)$. $\mathbf{n}$ Jejunal section of IR group showing marked decrease in number of goblet cells with depletion of mucin throughout the jejunal mucosa $(\times 100)$. o Jejunal section of IR + GABA group showing nearly normal number of goblet cells with normal mucin content $(\times 100)$ 
Table 1 Morphometric parameters in the studied groups

\begin{tabular}{llllll}
\hline & No. of villi & No. of crypts & Mucosal thickness $(\mu \mathrm{m})$ & Mucosal thickness $(\mu \mathrm{m})$ & Outer intestinal circumference $(\mu \mathrm{m})$ \\
\hline Control & 50 & 135 & $56.35 \pm 16.54$ & $7.72 \pm 0.76$ & 1379.46 \\
GABA & 45 & 130 & $50.22 \pm 15.23$ & $7.13 \pm 0.75$ & 1334.52 \\
$\mathbb{I R}$ & $35^{*}$ & $95^{*}$ & $24.46 \pm 8.90^{*}$ & $5.15 \pm 0.66^{*}$ & $1231.66^{*}$ \\
IR + GABA & 38 & 110 & $48.36 \pm 13.85$ & $6.24 \pm 0.71$ & 1428.73 \\
\hline
\end{tabular}

Values are expressed as means \pm standard deviation $(n=10)$

*Significantly different from the control at $P<0.05$

compared with those of irradiated group (Tables 3 and 4).

\section{Discussion}

Nowadays, ionizing radiation exposure is almost unavoidable (either accidental or intentional) because of the variability of applications of ionizing radiation including medical diagnostic and therapeutic purposes in addition to the occupational exposure to radiation which is common in the workers in these fields. Radiotherapy, an important modality in treating cancers, induces serious side effects that result from radiation-induced damage to normal tissues and may limit the therapeutic doses of ionizing radiation and thereby restrict the efficacy of the treatment (Baliga et al., 2012). The small intestine is a radiosensitive organ. A new challenge for physicians is to ensure the patient quality of life by protecting normal cells and tissues from radiation damage while improving anticancer effectiveness (Weichselbaum, 2005).

Results of the present study revealed that whole body 6 Gy of gamma irradiation of rats caused severe intestinal degenerative changes represented by intestinal mucosal damage in the form of subepithelial space at the apex of some villi with capillary congestion; other villi showed massive lifting of the epithelial layer from the lamina propria. Some denuded villi with exposed lamina propria and dilated capillaries were also seen with increased cellularity of the lamina propria. In addition, atrophy of both crypts and villi with a reduction in the number of both goblet and Paneth cells which appeared degranulated were also depicted. Similar findings were described before (Wang et al., 2013). All these observations of the current experiment resemble an intestinal mucositis which is a common adverse effect in patients undergoing radiation therapy. Histochemical observations of the current experiment revealed a marked decrease in PAS +ve materials throughout the jejunal tissue and increased PAS +ve materials were limited to the areas where few numbers of goblet cells with their mucin and Paneth cells found while their granules were reported earlier to be composed of carbohydrate-protein complexes (Ergun, Ergun, Asti, \& Kurum, 2003). These observations were corroborated by previous studies of other investigators where submucosal oedema, hyperemia, and infiltration of lamina propria with inflammatory cellular infiltration were found following 5 Gy gamma radiation exposure (Kanter \& Akpolat, 2008; Akpolat, Kanter, \& Uzal, 2009). Paneth cell reduction following gamma radiation exposure was also reported before (Eltahawy, Abunour, \& Elsonbaty, 2012).

In the small intestine, stem cells reside in the crypts of Lieberkühn produce progenitor cells that differentiate into four different cell types, including goblet cells, enterocytes, enteroendocrine cells, and Paneth cells (Haegebarth \& Clevers, 2009). Paneth cells produce defensins to protect the small intestine against the bacterial entrance. However, stem cells have also been shown to decrease bacterial entrance (Van der Flier \& Clevers, 2009). Moreover, Paneth cells release factors that help modulate the epithelial stem and progenitor cells that exist in the crypts of Lieberkühn and renew the small intestinal epithelium. Reduction of Paneth cells following 6 Gy gamma radiation exposure of rats may be attributed to small intestine inflammatory restoration during the post-irradiation time (Gorbunov, Garrison, \& Kiang, 2010), where dysfunction of Paneth cell may contribute to the pathogenesis process of inflammatory bowel disease (Clevers \& Bevins, 2013).

Morphometric analysis of the present experiment showed a significant decrease in the number of villi and crypts with high proliferation index, elevated tetraploid value, and increased mean nuclear area following $6 \mathrm{~Gy}$

Table 2 DNA cytometry parameters in the studied groups

\begin{tabular}{llllll}
\hline & Diploid value $\%$ & Proliferation index & Tetraploid value $\%$ & Aneuploid value $\%$ & ${\text { Nuclear area }\left(\mu m^{2}\right)}^{2}$ \\
\hline Control & $75.676 \%$ & $18.018 \%$ & $6.306 \%$ & $0.0 \%$ & 27.74 \\
GABA & $80.237 \%$ & $15.961 \%$ & $4.402 \%$ & $0.0 \%$ & 25.23 \\
IR & $53.773 \%$ & $30.189 \%$ & $13.208 \%$ & $2.83 \%$ & 33.75 \\
IR + GABA & $84.684 \%$ & $11.712 \%$ & $3.604 \%$ & $0.0 \%$ & 23.92 \\
\hline
\end{tabular}


Table 3 Influence of GABA (200 mg/Kg b.wt; 3 weeks) on oxidant biomarkers values in jejunum of 6 Gy whole body gamma-irradiated rats

\begin{tabular}{lll}
\hline $\begin{array}{l}\text { Parameter } \\
\text { Groups }\end{array}$ & $\begin{array}{l}\text { AOPP } \\
(\mu \mathrm{mol} / \mathrm{L})\end{array}$ & $\begin{array}{l}\text { MDA } \\
(\mathrm{nmol} / \mathrm{g})\end{array}$ \\
\hline Control & $164.90 \pm 6.59$ & $112.50 \pm 7.65$ \\
GABA & $158 \pm 5.19$ & $103.80 \pm 11.63$ \\
P1 & $(-8 \%)$ & $(-8 \%)$ \\
& NS & $<0.05$ \\
IR & $285.80 \pm 6.76$ & $158.70 \pm 6.75$ \\
P1 & $(73 \%)$ & $(46 \%)$ \\
& $<0.001$ & $<0.001$ \\
IR + GABA & $248.20 \pm 19.97$ & $116.70 \pm 11.88$ \\
P1 & $(51 \%)$ & $(4 \%)$ \\
P2 & $<0.001$ & NS \\
& $<0.001$ & $<0.001$ \\
\hline
\end{tabular}

Values are expressed as Means \pm Standard Deviation $(n=10)$. Values between brackets show a percentage of change from Control. P1: significance vs control. P2: significance vs respective group (IR) not receiving GABA. NS: non-significant. $P<0.001$ highly significant

of gamma radiation exposure indicating the high cellular turnover as a result of irradiation. In addition, the mucosal thickness, muscle layer, and the outer intestinal circumference decreased significantly post exposure demonstrating the damaging effects of radiation on the intestinal wall. The current results showed that these parameters are valuable to be measured in the evaluation of radiation effects. Kim et al. (2012) indicated that they are very sensitive biodosimetric markers after irradiation process. Acute effects of irradiation on the intestinal mucosa may be attributed to inhibition of mitotic divisions in the Lieberkühn crypts, and the loss of proliferative functions results in drop in the development of the small intestine epithelium and reduces the small intestine permeability to gut bacteria and antigens, which

Table 4 Influence of GABA (200 mg/Kg b.wt; 3 weeks) on antioxidants biomarkers values in jejunum of 6 Gy whole body gamma-irradiated rats

\begin{tabular}{lll}
\hline $\begin{array}{l}\text { Parameter } \\
\text { Groups }\end{array}$ & $\begin{array}{l}\mathrm{GSH}-\mathrm{Px} \\
(\mathrm{GSH} / \mathrm{min} / \mathrm{g} \\
\text { fresh tissue) }\end{array}$ & $\begin{array}{l}\text { Catalase } \\
\left(\mu \mathrm{mol} \text { of } \mathrm{H}_{2} \mathrm{O}_{2}\right. \\
\text { consumed/min/ } \\
\text { mg protein) }\end{array}$ \\
\hline Control & $16.62 \pm 0.37$ & $13.37 \pm 0.74$ \\
GABA & $16.50 \pm 0.46$ & $13.66 \pm 1.38$ \\
P1 & $(-0.7 \%)$ & $(2 \%)$ \\
IR & NS & NS \\
P1 & $12.70 \pm 1.34$ & $2.93 \pm=0.54$ \\
& $(-24 \%)$ & $(-78 \%)$ \\
IR + GABA & $<0.001$ & $<0.001$ \\
P1 & $15.54 \pm 1.04$ & $6.45 \pm 1.61$ \\
P2 & $(-6 \%)$ & $(-52 \%)$ \\
& $<0.05$ & $<0.001$ \\
Vates & $<0.001$ & $<0.001$
\end{tabular}

Values are expressed as Means \pm Standard Deviation $(n=10)$. Values between brackets show a percentage of change from Control. P1: significance vs control. P2: significance vs respective group (IR) not receiving GABA. NS: non-significant. $P<0.001$ highly significant may intensify mucosal inflammation and dysfunction or lead to bacteremia (Son et al., 2013).

The current study showed that 6 Gy whole body gamma irradiation of male albino rats triggered oxidative stress indicated by a highly significant increase in the oxidant biomarkers (AOPP and MDA) and a highly significant decrease in antioxidant enzyme activity (CAT and GSH-Px). Injurious effects of radiation are caused mainly by the overproduction of reactive oxygen species (ROS), which are products of the respiratory chain in mitochondria (Nita \& Grzybowski, 2016), damaged antioxidant system, or a combination of these issues. These ROS interact with living cell components producing harmful free radicals leading to lipid peroxidation and DNA damage processes (Jagetia \& Reddy, 2005). ROS can also interrupt the balance of endogenous protective systems, including enzymic antioxidants (CAT and GSHPx) defense system (Prasad, Menon, Vasudev, \& Pugalendi, 2005). The increase in the oxidant biomarkers in the present work has been reported before (Yurut-Caloglu et al., 2015). The increase of MDA in the present experiment may be attributed to the interaction of $\mathrm{OH}$, a by-product of water radiolysis post gamma radiation exposure, with the cellular membrane polyunsaturated fatty acids (Spitz, Azzam, Li, \& Gius, 2004). Also, the increase in AOPP may be due to the interaction of ROS with various cellular proteins (Meaney et al., 2008). Moreover, the decrease in antioxidant (CAT and GSH-Px) activity following gamma radiation exposure was reported earlier by Saada, Rezk, and Eltahawy (2010), and such decrease may be attributed to the enzymatic action of these enzymes on free radicals formed by radiation during oxidative damage and lipid peroxidation where water radiolysis results in increased amounts of $\mathrm{OH}$. and $\mathrm{H}_{2} \mathrm{O}_{2}$ that lead to oxidation and inactivation of these enzymes (Farag \& Darwish, 2016), which is their consumption by increased ROS production; enzyme chemical bonds break as a direct effect of gamma radiation or enzyme synthesis inhibition (Osman, Darwish, \& Farag, 2011).

In this study, the administration of GABA to normal male albino rats for 3 weeks was of none valuable effects on the studied parameters which corroborate previous findings that chronic administration of GABA at up to $1 \mathrm{~g} / \mathrm{kg} /$ day in rats was well tolerated without signs of injury for a period of up to 1 year (Yoshikuni, 2008). GABA administration reduced the degenerative changes in the jejunal epithelial cells and significantly improved the survival of villi and crypts in gamma-irradiated rats. The injury of the Paneth cells and the distortion of goblet cells were mainly absent in GABA-treated rats. In addition, gastric administration of GABA after whole body gamma irradiation reduced the oxidative stress where GABA improved GSH-Px activity (Huang et al., 
2011). Improvement may be due to increased GABA level which may promote the increase of glutamate level in the entire body. Glutamate, the raw material for glutathione synthesis in the antioxidation system, recover and maintain the reduced glutathione level, by this way improving the activity of GSH-Px in the antioxidation system (Chen, Tang, Sun, \& Xie, 2013). Moreover, the modulator role of GABA following radiation exposure may also be attributed to its antioxidant and free radical-scavenging activities (Deng et al., 2013; Eltahawy, Abd El-Hady, Badawi, \& Hammad, 2017). Thus, GABA can attenuate various morphological, histopathological, and biochemical changes resulting from intestinal injury following radiation exposure demonstrating that GABA provides a significant ameliorative effect against intestinal injury following irradiation process.

\section{Conclusions}

In conclusion, the results of the biochemical investigation were in alliance with the histopathological findings where gastric administration of GABA was found to offer an advantageous treatment against gammairradiation-induced small intestine oxidative stress in rats, probably by utilizing ameliorative effects via its antioxidant and free radical-scavenging activities. Its mechanisms need to be further investigated. Also, further clinical studies are required to assess the safety and benefits of GABA before use in human beings and approval by Food and Drug administration (FDA).

\section{Acknowledgements \\ The authors are grateful to all members in the Radiation Biology Department, National Centre for Radiation Research and Technology (NCRRT), and Pathology Department, National Research Centre (NRC).}

\section{Funding}

This study received no specific grant from any funding agency within the public, commercial, or not-for-profit sectors.

\section{Authors' contributions}

NAE and AMAEH designed the work and collected the data. MAB and AMAEH analyzed and interpreted the data. AMAEH and HSG wrote the manuscript. Revision of the article and final approval of the version to be published was done by all authors.

\section{Ethics approval}

All animal procedures were carried out in accordance with the Ethics Committee of the National Research Centre conformed to the "Guide for the Care and Use of Laboratory Animals" published by the US National Institutes of Health.

\section{Competing interests}

The authors declare that they no competing interests.

\section{Publisher's Note}

Springer Nature remains neutral with regard to jurisdictional claims in published maps and institutional affiliations.

\section{Author details}

${ }^{1}$ Radiological Imaging Technology Department, Faculty of Applied Medical Sciences, Misr University for Science and Technology (MUST), 6th of October,
Giza, Egypt. ${ }^{2}$ Pathology Department, National Research Centre, Dokki, Cairo 12622, Egypt. ${ }^{3}$ Radiation Biology Department, National Centre for Radiation Research and Technology (NCRRT), Egyptian Atomic Energy Authority (EAEA), Cairo, Egypt.

Received: 28 May 2017 Accepted: 16 August 2017

Published online: 26 December 2017

\section{References}

Akpolat M., Kanter M., \& Uzal M. C. (2009). Protective effects of curcumin against gamma radiation-induced ileal mucosal damage. Archives of Toxicology, 83, 609-617.

Baliga M. S., Haniadka R., Pereira M. M., Thilakchand K. R., Rao S., \& Arora R. (2012). Radioprotective effects of Zingiber officinale Roscoe (ginger): past, present and future. Food \& Function, 3, 714-723.

Bancroft J. D., \& Gamble M. (2008). Theory and practice of histological techniques (6th ed., ). Churchill Livingstone, China: Elsevier.

Chen Z., Tang J., Sun Y. Q., \& Xie J. (2013). Protective effect of Y-aminobutyric acid on anti oxidation function in intestinal mucosa of Wenchang chicken induced by heat stress. J. Anim. Plant. Sci., 23, 1634-1641.

Clevers H. C., \& Bevins C. L. (2013). Paneth cells: Maestros of the small intestinal crypts. Annual Review of Physiology, 75, 289-311.

Czito B., \& Willett C. (2010). Radiation injury. In M. Feldman, S. Lawrence, L. Friedman, \& L. Brandt (Eds.), Sleisenger and Fordtran's gastrointestinal and liver disease. Pathophysiology, diagnosis, management (9th ed., ). Philadelphia: Saunders.

Deng Y., Wang W., Yu P., Xi Z., Xu L., Li X., ... He N. (2013). Comparison of taurine GABA, Glu, and Asp as scavengers of malondialdehyde in vitro and in vivo. Nanoscale Research Letters, 8, 190.

Desouky O., Ding N., \& Zhou G. (2015). Targeted and non-targeted effects of ionizing radiation. Journal of Radiation Research and Applied Sciences, 8, 247-254.

Dong H., Kumar M., Zhang Y., Gyulkhandanyan A., Xiang Y. Y., Ye B., ... Wang Q. (2006). Gamma-aminobutyric acid up- and down regulates insulin secretion from beta cells in concert with changes in glucose concentration. Diabetologia, 49, 697-705

Drury R. A., \& Wallington E. A. (1980). Carleton's histological techniques (5th ed., pp. 653-661). New York Toronto: Oxford University Press. London.

Elphick D. A., \& Mahida Y. R. (2005). Paneth cells: Their role in innate immunity and inflammatory. Gut, 54, 1802-1809.

Eltahawy N., Abunour S., \& Elsonbaty S. (2012). Effectiveness of Punica granatum juice in ameliorating oxidative damage and ultrastructural changes in Paneth cells of rat intestine. Journal of Pharmacy \& Bioallied Sciences, 4, 25-31.

Eltahawy N., Abd El-Hady A. M., Badawi M., \& Hammad A. (2017). Gamma amino butyric acid ameliorates jejunal oxidative damage in diabetic rats. Indian Journal of Pharmaceutical Education and Research, 51(4), 588-596.

Ergun E., Ergun L., Asti R. N., \& Kurum A. (2003). Light and electron microscopic morphology of Paneth cells in the sheep small intestine. Revue de Médecine Vétérinaire, 154, 351-355.

Farag M. F. S., \& Darwish M. M. (2016). Possible impact of antioxidant properties of cocoa (Theobroma Cacao L.) against irradiation-induced some biochemical disorders in rats. Arab Journal of Nuclear Science and Applications, 94, 151-158.

George W., \& William G. (1980). Statistical methods (7th ed., p. 217).

Gorbunov N. V., Garrison B. R., \& Kiang J. G. (2010). Response of crypt Paneth cells in the small intestine following total body $\mathrm{Y}$-irradiation. International Journal of Immunopathology and Pharmacology, 23, 1111-1123.

Grdina D. J., Murley J. S., \& Kataoka Y. (2002). Radioprotectants: Current status and new directions. Oncology, 63, 2-10.

Haegebarth A., \& Clevers H. (2009). Wnt signaling, lgr5, and stem cells in the intestine and skin. The American Journal of Pathology, 174, 715-721.

Hauer-Jensen M., Wang J., Boerma M., Fu Q., \& Denham J. W. (2007). Radiation damage to the gastrointestinal tract: Mechanisms, diagnosis, and management. Current Opinion in Supportive and Palliative Care, 1, 23-29.

Hauer-Jensen M., Denham J. W., \& Andreyev H. J. (2014). Radiation enteropathy - pathogenesis, treatment, and prevention. Nature Reviews. Gastroenterology \& Hepatology, 11, 470-479.

Hori T., Gardner L. B., Hata T., Chen F., Baine A. M., Uemoto S., ... Nguyen J. H. (2013). Pretreatment of liver grafts in vivo by $\gamma$-aminobutyric acid receptor regulation reduces cold ischemia/warm reperfusion injury in rat. Pretreatment of liver grafts in vivo by $\mathrm{Y}$-aminobutyric acid receptor 
regulation reduces cold ischemia/warm reperfusion injury in rat. Annals of Transplantation, 18, 299-313.

Huang H. L., Zhao W. J., Zou X. T., Li H., Zhang M., \& Dong X. Y. (2011). Effect of $Y$ aminobutyric acid on incubation, immunity and antioxidant activity in pigeon. Chinese Journal of Veterinary Science, 9, 1327-1331.

Hyland N. P., \& Cryan J. F. (2010). A gut feeling about GABA: Focus on GABAB receptors. Frontiers in Pharmacology Gastrointestinal Pharmacology, 1, 1-9.

Jagetia G. C., \& Reddy T. K. (2005). Modulation of radiation induced alteration in the antioxidant status of mice by naringin. Life Sciences, 77, 780-794.

Kanter M., \& Akpolat M. (2008). Vitamin C protects against ionizing radiation damage to goblet cells of the ileum in rats. Acta Histochemica, 110, 481-490.

Kiernan J. A. (1981). Histological and Histochemical methods, theory and practice (). New York: Pergamon Press.

Kim J. S., Ryoo S. B., Heo K., Kim J. G., Son T. G., Moon C., ... Yang K. (2012) Attenuating effects of granulocyte-colony stimulating factor (G-CSF) in radiation induced intestinal injury in mice. Food and Chemical Toxicology, 50, 3174-3180.

Meaney E., Vela A., Samaniego V., Meaney A., Asbún J., Zempoalteca J. C., .. Ceballos G. (2008). Metformin, arterial function, intima-media thickness and nitroxidation in metabolic syndrome: The mefisto study. Clinical and Experimental Pharmacology and Physiology, 35, 895-903.

Müller C. A., Autenrieth I. B., \& Peschel A. (2005). Innate defenses of the intestinal epithelial barrier. Cellular and Molecular Life Sciences., 62, 1297-1307.

Nakagawa T., Yokozawa T., Kim H. J., \& Shibahara N. (2005). Protective effect of gamma aminobutyric acid in rats with streptozotocin-induced diabetes. Journal of Nutritional Science and Vitaminology, 51, 278-282.

Necheles T. F., Boles T. A., \& Allen D. M. (1968). Erythrocyte glutathioneperoxidase deficiency and hemolytic disease of the newborn infant. The Journal of Pediatrics, 72, 319-324.

Nita, M., Grzybowski, A., 2016. The role of the reactive oxygen species and oxidative stress in the pathomechanism of the age-related ocular diseases and other pathologies of the anterior and posterior eye segments in adults. Oxidative Medicine and Cellular Longevity, 2016:3164734. Doi: https://doi. org/10.1155/2016/3164734. Epub 2016 Jan 10.

Osman N. N., Darwish M. M., \& Farag M. F. S. (2011). Possible ameliorative effect of chicory extract (Cichorium intybus) on radiation-induced oxidative damage in rats' heart. Journal of Radiation Research and Applied Sciences, 4(A), $1121-1137$

Ouellette A. J., Satchell D. P., Hsieh M. M., Hagen S. J., \& Selsted M. E. (2000). Characterization of luminal Paneth cell alpha-defensins in mouse small intestine: Attenuated antimicrobial activities of peptides with truncated amino termini. The Journal of Biological Chemistry, 275, 33969-33973.

Prasad N. R., Menon P., Vasudev V., \& Pugalendi K. V. (2005). Radioprotective effect of seasamol on $\gamma$-radiation induced DNA damage, lipid peroxidation and antioxidants level in cultured human lymphocytes. Toxicology, 209, 225-235.

Saada H. N., Rezk R. G., \& Eltahawy N. A. (2010). Lycopene protects the structure of the small intestine against gamma-radiation-induced oxidative stress. Phytotherapy Research, 24, 204-208.

Sinha A. K. (1972). Colorimetric assay of catalase. Analytical Biochemistry, 47, 389-394.

Soltani N., Qiu H., Aleksic M., Glinka Y., Zhao F., Liu R., ... Wang Q. (2011). GABA exerts protective and regenerative effects on islet beta cells and reverses diabetes. Proceedings of the National Academy of Sciences of the United States of America, 108, 11692-11697.

Son T. G., Gong E. J., Bae M. J., Kim S. D., Heo K., Moon C., ... Kim J. S. (2013). Protective effect of genistein on radiation-induced intestinal injury in tumor bearing mice. BMC Complementary and Alternative Medicine, 13, 103.

Spitz D. R., Azzam E. I., Li J. J., \& Gius D. (2004). Metabolic oxidation/reduction reactions and cellular responses to ionizing radiation: $A$ unifying concept in stress response biology. Cancer Metastasis Reviews, 23, 311-322.

Tian J., Dang H. N., Yong J., Chui W. S., Dizon M. P., Yaw C. K., ... Kaufman D. L. (2011). Oral treatment with $\gamma$-aminobutyric acid improves glucose tolerance and insulin sensitivity by inhibiting inflammation in high fat diet-fed mice. Plos One, 6, 25338.

Van der Flier L. G., \& Clevers H. (2009). Stem cells, self-renewal, and differentiation in the intestinal epithelium. Annual Review of Physiology, 71, 241-260.

Wang F. Y., Watanabe M., Zhu R. M., \& Maemura K. (2004). Characteristic expression of gamma-aminobutyric acid and glutamate decarboxylase in rat jejunum and its relation to differentiation of epithelial cells. World Journal of Gastroenterology, 10, 3608-3611.

Wang Y. J., Liu W., Chen C., Yan L. M., Song J., Guo K. Y., ... Gu W. W. (2013). Irradiation induced injury reduces energy metabolism in small intestine of Tibet minipigs. Plos One, 8, e58970.
Watanabe M., Maemura K., Kanbara K., Tamayama T., \& Hayasaki H. (2002). GABA and GABA receptors in the central nervous system and other organs. International Review of Cytology, 213, 1-47.

Weichselbaum R. (2005). Radiation's outer limits. Nature Medicine, 11, 477-478.

Witko-Sarsat V., Friendlander M., Capelliere-Blandin C., Nguyen-Khoa T., Zing J., Jungers P., ... Descamps-Latscha B. (1996). Advanced oxidation protein products as a novel marker of oxidative stress in uremia. Kidney International, 49, 1304-1313.

Yoshikuni Y. (2008). FDA GRAS notice for gamma-amino butyric acid (GABA) (). Pharma Foods International Co., Ltd.

Yoshioka T., Kawada K., Shimada T., \& Mori M. (1979). Lipid peroxidation in maternal and cord blood and protective mechanism against activated oxygen toxicity in the blood. American Journal of Obstetrics and Gynecology, $135,372-376$.

Yurut-Caloglu V., Caloglu M., Eskiocak S., Tastekin E., Ozen A., Kurkcu N., ... Uzal C. (2015). Comparison of the protective roles of $L$-carnitine and amifostine against radiation-induced acute ovarian damage by histopathological and biochemical methods. Journal of Cancer Research and Therapeutics, 11, 447-453.

\section{Submit your manuscript to a SpringerOpen ${ }^{\circ}$ journal and benefit from:}

- Convenient online submission

- Rigorous peer review

- Open access: articles freely available online

- High visibility within the field

- Retaining the copyright to your article

Submit your next manuscript at springeropen.com 